\title{
To Blend or to Compose: a Debate about Emotion Structure
}

\author{
Dr. Larry A. Herzberg \\ Philosophy Department \\ University of Wisconsin - Oshkosh \\ herzberg@uwosh.edu
}

What follows is the final proof of the chapter that I contributed to Dynamicity in Emotion Concepts, Paul A. Wilson (ed.), Vol. 27 of the interdisciplinary Lodz Studies in Language series (edited by Barbara Lewandowska-Tomaszczyk), published by Peter Lang, Frankfurt: 2012. I am making it available here because several researchers in various countries have reported to me that the book is currently unavailable in their libraries, and the chapters are not yet available in the usual online databases.

As far as I can tell, the only discrepancies between this version and the published version concern the particular last and first lines that appear on particular pages.

Note first that while the pages of this proof are numbered $65-86$, the pages of the publication are numbered 73-94. In addition, some lines that appear as the last lines of pages in this draft occur as the first lines of the subsequent pages in the publication. Here is a catalog of the differences:

The last line of p. 70 in this proof $=$ the first line of p. 79 in the publication.

The last line of p. 71 in this proof $=$ the first line of p. 80 in the publication. ....and so on until...

The last two lines of p. 78 in this proof = the first two lines of p. 87 in the publication. ....and so on until...

The last line of p. 82 in this proof = the first line of p. 91 in the publication.

The pages are $100 \%$ in sync starting at the end of p. 83 in the proof and the end of p. 91 in the publication.

Please note that these last/first line discrepancies occur only in the body of the text; the footnotes all appear in their entirety on the relevant pages. 


\title{
To Blend or to Compose: a Debate about Emotion Structure
}

\author{
Larry A. Herzberg
}

\begin{abstract}
:
An ongoing debate in the philosophy of emotion concerns the relationship between two prima facie aspects of emotional states. The first is affective: felt and/or motivational. The second, which I call object-identifying, represents whatever the emotion is about or directed towards. "Componentialists" - such as R. S. Lazarus, Jesse Prinz, and Antonio Damasio - assume that an emotion's object-identifying aspect can have the same representational content as a nonemotional state's, and that it is psychologically separable or dissociable from the emotion's affective aspect. Some further hold that emotions have no objectidentifying aspects of their own, and can properly be said to be about things only in virtue of their associations with other mental states (such as beliefs or perceptions). By contrast, "blenderists" - such as Peter Goldie, York Gunther, and Matthew Ratcliffe - insist that the two aspects are indissociable, because the affective aspect "infuses" the object-identifying aspect, altering the subject's concept or percept of the object. As a result, an emotion's object-identifying aspect cannot possibly have the same representational content as any nonemotional state's. I argue that the strongest blenderist arguments fail to rule out plausible componentialist alternatives, and that the blenderists' broader motivations are orthogonal to structural issues.
\end{abstract}

\section{Keywords:}

Emotion, structure, affect, feeling, representation, content, intentionality, Goldie, Gunther, Ratcliffe.

\section{Introduction}

Emotion ascriptions typically have two grammatically independent parts. For instance, if I say that I am (i) glad that my computer is working, "glad" is detachable from "my computer is working" in the sense that I may later report that I am (ii) sad that my computer is working, or (iii) glad that it is not raining. Furthermore, "glad" seems to have the same meaning in (i) and (iii), and "my computer is working" seems to have the same meaning in (i) and (ii). The debate that I discuss below concerns whether such linguistic points reflect 
psychological facts about emotion structure. " Componentialists", as I call them, hold that they do. On their views, the states to which emotion ascriptions refer have at least two dissociable parts. ${ }^{2}$ One is affective - felt and/or motivational. The other represents the property, object, person, event, or situation that the affective aspect is about or "directed at". For simplicity's sake, I call this the emotion's object-identifying aspect, and refer to it as having "object-identifying representational content". ${ }^{3}$ On componentialist views, (i) and (iii) refer to emotions with the same type of affective aspect, and (i) and (ii) refer to emotions with the same object-identifying aspects. Furthermore, those objectidentifying aspects employ the very same concepts - and hence have the same representational content - as a non-emotional judgement that my computer is working.

By contrast, "blenderists" find the linguistic facts illustrated by (i)-(iii) misleading, arguing that an emotion's affective and object-identifying aspects are indissociable. On their views, an emotion's affective aspect blends with its object-identifying aspect, instantiating a unique class of affect-infused concepts or percepts, and so constituting a state whose representational content cannot be identical to any non-emotional state's. Peter Goldie $(2000 ; 2002)$ tries to support such a view with both phenomenological claims about the way it seems to be in an emotional state (or to engage in an activity emotionally as opposed to nonemotionally), and a conceptual argument similar to Frank Jackson's (1986) "black-and-white-Mary" thought experiment. Just as Mary - who has learned all of the physical facts about color while living in a black-and-white room supposedly gains a new "phenomenal concept" of red upon leaving the room and seeing a red object for the first time, Goldie argues that ice-scientist Irene gains a new, affect-infused concept of ice's dangerousness once she has slipped and fallen on ice. If a term like "dangerous" can be ambiguous between affectneutral and affect-infused concepts of danger, this might support blenderism by helping to explain away the apparent similarities in emotion ascriptions like (i) and (ii). For if an affect-infused concept differs from an affect-neutral concept, then one might well conclude that a gladness-infused concept differs from a sadness-infused concept.

York Gunther $(2003,2004)$ sets forth a similarly inventive argument for blenderism, based on the purported inability of emotionally expressive

1 "Structure", as I am using it here, is a mereological term that cuts across logical and ontological categories.

2 By "dissociable" I mean that they could exist independently of each other.

3 Hereafter I will omit the 'representational', and refer simply to this aspect's objectidentifying content. Componentialists disagree on the question of whether such content must be conceptual, or whether it can also be perceptual. Also, as I will discuss below, some allow an emotion's affective aspect to have (perceptual) representational content, but not of the object-identifying kind. 
utterances to have disjunctive or conditional content, and hence to exhibit "full logical complexity". For instance, he argues that while I can properly believe that if I come late, I will make a quiet entrance, I cannot properly apologize (or express regret for the fact) that if I come late, I will make a quiet entrance. This apparent limitation on the logical form of emotionally expressive utterances shows, he thinks, that such expressions violate the "force/content" distinction that facilitates communication by allowing instances of different types of speech acts - such as questions, answers, and commands - to have the same content. And the violation of this distinction, Gunther argues, supports a blenderist view of emotion structure. So, on both Goldie's and Gunther's views, (i)-(iii) should be interpreted as referring to indissociable blends of affective and objectidentifying aspects that have much less in common with each other than their ascriptions suggest.

To evaluate blenderism, I first discuss the sorts of componentialist theories that would have to be radically revised or abandoned were the program to succeed. Since they are quite explicit about their structural views, I focus here on the theories of R. S. Lazarus (1991; 1999), Jesse Prinz (2004), and Antonio Damasio (1994; 2004). Secondly, I evaluate what I take to be Goldie's and Gunther's strongest arguments for blenderism, and argue that they are ultimately unconvincing given the componentialist alternatives. Thirdly, to better understand why such philosophers might be drawn to this somewhat unorthodox view, I consider their explicitly stated motivations. Goldie and Gunther clearly view blenderism as a defense of the personal, phenomenological viewpoint against the impersonal stance of psychology and contemporary philosophy of mind. Matthew Ratcliffe (2005a; 2005b) additionally views blenderism as an integral part of a broader pragmatist conception of how "organismic concerns" shape experiences of the world. ${ }^{4}$ These motivations are certainly weighty enough. However, after considering how a teleosemanticist like Ruth Millikan (1984; 2004) approaches such concerns from a quite different perspective, I conclude that the blenderists' motivations are actually orthogonal to the debate about emotion structure.

\section{Componentialist views of emotion structure}

While componentialism about emotion structure arguably traces back to Aristotle (Cf. Rhetoric, Book II) and continues through the works of modern philosophers like Descartes (1649/1985) and David Hume (1739/1975), R. S.

4 Ratcliffe (2005a) offers an intriguing - but, I think, ultimately unconvincing - argument for blenderism from an analogy between emotion and touch that I hope to discuss in a future paper. 
Lazarus (1991) explicates the view in a contemporary way that is consistent with his own cognitive appraisal theory of emotion, using anger as an example:

...emotion is a superordinate concept that includes cognition in a part-whole relationship... The cognitive activity, A - namely, blaming someone for an offense - combines in an emotion with the physiological reactions and action tendencies, $\mathrm{B}$, to form an organized configuration, $\mathrm{AB}$. The blame causes the emotion, anger, and is also a continuing part of it. To say that anger $(A B)$ - which includes thoughts of blaming someone for an offense (A) - is the cause of the angry reaction $(A B)$ makes no sense unless we realize that a component of the configuration, $\mathrm{A}$, can produce another subsequent $\mathrm{AB}$, of which $\mathrm{A}$ is an essential part.

(R. S. Lazarus, 1991: 173-174)

Although Lazarus does not mention feeling per se in this passage, he later makes it clear that he views "subjective experience" or "affect" as an essential part of the "emotional response configuration" that includes physiological reactions and action tendencies (R. S. Lazarus, 1991: 210). The componentiality of emotion here reflects a division of psychological labor: evaluative thoughts, which by themselves may be affectively neutral and motivationally inert, cause and then combine with felt motivational impulses. This combination is required for each of the components to effectively fulfill their functions: "Thought without motivation is emotionless. Motivation without thought is drive or energy, without the direction that cognition provides" (Lazarus, 1999: 10). Ultimately, Lazarus views emotions as part of an ongoing transactional process, enabled by a "cognitive-motivational-emotive" system, that allows one to recognize relations between one's goals (concerns or interests) and one's natural and social environments, and finally to react appropriately (Lazarus, 1991: 210).

For Lazarus, all of an emotion's representational content or intentionality resides in an evaluative judgment - an "appraisal outcome" - that represents the relationship between oneself and one's environment in terms of a core relational theme. Emotion types are distinguished by core relational themes, and an appraisal outcome's core relational theme causally determines an emotion's affective component. For instance, if an event is cognitively appraised in terms that can properly be summarized as a demeaning offense to me or mine, this judgment normally causes an affective response of anger, a felt impulse associated with particular physiological conditions. This affective component immediately combines psychologically with the eliciting cognition to yield an emotion with object-identifying content, one that typically guides the impulse towards the offender.

Prinz (2004) modifies Lazarus's theory in several important ways. He agrees that emotions represent core relational themes, but he denies that 
cognitive appraisals or evaluative judgments are necessary for them to do this. Rather, drawing from both William James' (1918) bodily-feeling theory of emotion and Fred Dretske's (1986) teleosemantic theory of representation, he argues that as a particular class of feelings, emotions represent - in the sense of detect - core relational themes by registering the bodily conditions that are reliably caused by situations instantiating those themes. The distinction between representation and registration is not unique to emotion; Prinz notes that they come apart in visual perception as well. For instance, "a state in the visual system registers a particular luminance discontinuity, but it represents an edge" (Ibid.: 58). The teleosemantic presupposition here is that a visual percept's representational content is constrained by its evolutionary utility. Representing luminance discontinuities would not be nearly as useful as representing the edges that reliably cause such discontinuities, so the relevant percepts represent edges, not luminance discontinuities. Similarly, detecting the sorts of bodily conditions that emotional feelings register would likely have little survival value, but detecting the significant organism-environment relations - core relational themes - that reliably cause those bodily conditions could be quite useful, so emotional feelings represent the latter. ${ }^{5}$

To help clarify the differences between Prinz's and Lazarus's views of emotion structure, consider a case of sadness. Lazarus holds that if I am to feel sad about a particular death, I must first cognitively evaluate it in terms that can be summarized as an irrevocable loss to me, the core relational theme of sadness. This evaluation then triggers (and subsequently combines with) an affective emotional response, resulting in a state of sadness with objectidentifying content. The affective and object-identifying aspects are equally parts of the emotion per se. By contrast, Prinz holds that a non-evaluative representation of a death can be sufficient to trigger the bodily changes that are felt as sadness - a feeling that by itself functions to detect the death as an irrevocable loss to me. This valent ${ }^{6}$ and representational feeling is the emotion per se. It can properly be said to be about the death only insofar as it remains associated with the representation that caused it, and since this association is

5 Artifactual examples that do not depend on natural selection can also be used to illustrate the registration/representation distinction. For instance, the ringing of an electronic doorbell is reliably caused by the presence of voltage in the doorbell circuit, and the ringing registers the presence of such voltage, but (by design and convention) it does not represent it; rather, the ringing represents the presence of someone pushing the doorbell button at the door.

6 For Prinz, an emotion's positive or negative valence helps to explain how such a feeling influences behavior. Unlike Lazarus, who views emotions as being constituted in part by immediately motivational "action-tendencies", Prinz argues that emotions motivate behavior only indirectly, after their valence markers - which command "more of this" or "less of that" - have been fed into a behavior selection system (such as conscious deliberation). Cf. Prinz 2004, Chapter 7. 
between the emotion and some state extrinsic to it, the same emotion could become associated with a different representation, providing it with a different object-identifying aspect. For instance, it could become associated with a more global representation of life, becoming a situationally-induced depression. In cases of anger and anxiety, the emotion's affective aspect might become inappropriately re-directed at a different person or event, one that played no role in causing the feeling. This sort of componentialism therefore provides a framework for explaining common cases of "displacement". It also coheres well with the apparent phenomenon of affective "inertia" (cf. de Sousa, 1987: 153154), wherein an emotional feeling persists even after the subject has recognized the falsity of the judgment that provided it with object-identifying content.

Our final componentialist, Antonio Damasio, distinguishes emotion, which he views entirely in neurophysiological terms, from feeling an emotion, a psychological phenomenon with componential structure-

Feeling [an emotion] consists of the joint perception of (a) the causative object; (b) the ensuing emotional state, and (c) the cognitive mode and related thoughts that may follow. Thus the intentionality of the emotions - the sense of what they are about - arises early in this physiological cycle with the perceptual definition of the emotionally-competent stimulus, and is completed in the feeling stage whose unfolding remains pointed to the emotionally-competent stimulus. ...feelings are, no doubt, about the causative external objects; but feelings are, in and of themselves, largely constituted by perceptions of bodily changes.

(Antonio Damasio, 2004: 5-6)

Contra Lazarus, the perception of the causative object here - the source of an emotional feeling's object-identifying content - need not be evaluative, and, contra Prinz, the sensational perception of the neurophysiological emotion represents nothing but perhaps the neurophysiological processes themselves. This passage leaves open the possibility of interpreting the "joint perception" that constitutes an emotional feeling as a blend, but in an earlier work Damasio explicitly argues against this hypothesis, first by describing the relationship between the two perceptions as a sort of juxtaposition (1994: 145), and then by

7 The difference between Prinz's and Lazarus's views here shows why referring simply to an emotion's "intentionality" or "intentional object" is ambiguous: one might be referring either to the emotion's core relational theme, or to whatever the emotion is directed towards, or to both. Although Prinz avoids such ambiguity by distinguishing between an emotion's formal and particular objects (the former being the emotion's core relational theme, the latter being whatever the emotion is directed towards), I prefer to distinguish more directly between an emotion's core relational theme and its object-identifying content, not only because this terminology seems more self-explanatory, but also because it avoids the metaphysical conundrums associated with talk of mental or intentional objects per se. 
presenting two quick componentialist arguments, one neurological, the other having to do with explanatory utility-

I chose this term ["juxtaposition"] because I think the image of the body proper appears after the image of the "something else" has been formed and held active, and because the two images remain separate, neurally... In other words, there is a "combination" rather than a "blending." It might be appropriate to use the term superposition for what seems to happen to the images of the body proper and "something else" in our integrated experience.

The idea that the "qualified" (a face) and the "qualifier" (the juxtaposed body state) are combined but not blended helps explain why it is possible to feel depressed even as one thinks about people or situations that in no way signify sadness or loss... Neurobiologically speaking, the unexplainable qualifiers affirm the relative autonomy of the neural machinery behind the emotions... (1994: 146)

How might neurologically juxtaposed - and psychologically dissociable images come to seem superposed in "integrated experience"? The analogy is only very rough, but consider what occurs when one transparent slide is set over another in a projector: the images are literally blended together on the screen. However, the images remain dissociable, since the slides are themselves separable. If this analogy is apt (aside from concerns about viewing the mind as a "Cartesian theater"), it nicely illustrates the danger of drawing psychological conclusions from phenomenological premises. As we are about to see, however, arguments for blenderism go well beyond phenomenological considerations.

\section{Goldie's adverbial, phenomenological, and "epistemic" arguments}

Peter Goldie distinguishes emotions from emotional episodes. On his view, an emotion has a "narrative structure" that "itself includes various past episodes of emotional experience, as well as various sorts of disposition to think, feel, and act, all of which can dynamically interweave and interact. What holds these diverse elements together is their being part of a narrative" (2000: 11). Clearly, Goldie's "emotions" are what most others would call partial biographies. So what concerns us here is rather what Goldie takes to be at the core of an emotional episode, namely a "feeling towards", which he initially describes as "thinking of with feeling, so that your emotional feelings are directed towards the object of your thought" (2000: 19).

Since "with" can indicate almost any kind of association, componentialists can accept this initial description. Indeed, defining the core of an emotional episode as "thinking of with feeling" is broad enough to be accepted by even the most extreme cognitivists about emotion (e.g., Solomon, 1984; or Gordon, 
1987), who view the felt aspects of emotional states as mere side effects or epiphenomenal accompaniments of the cognitive aspects. However, Goldie makes it clear that it is precisely such "add-on" views he is opposing-

Consider doing these things unemotionally: striking a blow; making love; seeking safety. Now consider, and contrast, acting when you act out of emotion: angrily striking the blow; making love passionately; fearfully running away. The phenomenology of such actions - what it is like for the agent - is fundamentally different in character. And an action done with feeling can be distinct in its phenomenology not just for the agent... one just has to think what it is like to be made love to with feeling for this to be obvious: it is not like being made love to without feeling, plus feeling. Acting out of emotion is not acting without emotion (explained by feelingless beliefs and desires) plus some added-on ingredient or ingredients. Rather, when an action is done out of an emotion, the whole action, and the whole experience of the action, is fundamentally different. (2000: 40)

Let us call this the adverbial argument against add-on theories. Perhaps it could also be used against componentialist theories (like Prinz's) that take feelings to be emotions, but view those feelings as gaining their object-identifying aspects from extrinsically related - and so "added-on" - states like beliefs. But how effective is this argument against either sort of theory? Goldie's point cannot merely be that acting with feeling (or "emotionally") changes the way the activity seems to the agent and others, for add-on theorists could certainly agree to that. After all, running in darkness seems different than running in light, but not because the running activity per se need be different. No, Goldie must be arguing that acting with feeling essentially alters the activity. If we accept this, then we might also accept that mental activities such as judging and perceiving are essentially altered by being done with feeling. Occurrent emotions might then be viewed as just such altered mental activities, essentially different than cognitive or perceptual activities done without feeling - perhaps because they are just such activities blended with feeling, rather than with feelings merely added on.

One problem with this as an argument for blenderism, rather than merely as an objection to add-on theories, is that one could accept that mental activities distinguished by attitude type - are essentially altered by being done with feeling, but insist that there need be no alteration of the activity's objectidentifying content. For instance, one could accept that believing angrily that John ignored $m e$ is an essentially different activity than simply believing that John ignored me, and yet not infer from this that the representational content of "John ignored me" must be different in the two cases. Indeed, Goldie later recognizes this, admitting that "it is always possible for an opponent to force all the difference into the attitude, so that the debate degenerates into a matter of 
competing intuitions" (P. Goldie, 2000, footnote 3, page 60). But a more basic problem here is Goldie's presupposition that, where $\mathrm{X}$ is an activity and $\mathrm{Y}$ a qualifier, "X-ing Y-ly" must refer to an essentially different activity than simply "X-ing", or even than "X-ing Z-ly", where $\mathrm{Y}$ and $\mathrm{Z}$ are opposite qualifiers. There are certainly some cases in which this presupposition seems true: given some fixed reference frame, "running quickly" perhaps refers to an essentially different activity than merely "running", or at least than "running slowly". But "running northerly" and "running" (or even "running southerly") do not similarly refer to essentially different activities, since they entail no difference in the running per se. Here the qualifiers merely signal alterations in the relational contexts of the activity, not in the activity itself. So Goldie needs to argue that locutions like "striking angrily" must be interpreted along the lines of "running quickly" rather than "running northerly", and this he has not done.

Goldie has a more direct phenomenological argument for his view that emotional feelings are "essentially bound up with content - with what the feeling is directed towards" (2000: 51). It begins from a case that Michael Stocker (1983: 21) uses to distinguish a mere "intellectual appreciation" of ice's dangerousness from the way in which one might feel about those same dangers after having fallen on ice. Goldie writes-

Putting this example in my terms, then I only thought of the ice as dangerous; now I feel fear towards the ice. ... The difference between thinking of $X$ as $Y$ without feeling and thinking of $X$ as $Y$ with feeling will not just comprise a different attitude towards the same content - thinking which earlier was without feeling and now is with feeling. The difference also lies in the content, although it might be that this difference cannot be captured in words. (2000:60)

Componentialists can certainly agree with Goldie that what it is like to think of the ice as dangerous has changed after one has slipped on ice; they need only resist the further conclusion that this entails changes in the content of the thought, and offer an account of the phenomenological difference in terms of an association between feelings of fear and the thought. They can also agree with Goldie's further point that "it does not follow from the fact that [two] thoughts are expressed in the same words that they have the same content" (Ibid.), for neither does it follow that they do not have the same content.

However, despite such difficulties, Goldie returns to the argument two years later (2002: 243), reframing it along the lines of Frank Jackson's (1986) "epistemic argument" against physicalism. He begins by recounting Jackson's central thought experiment. Mary is a scientist who has learned everything there is to know about the physics of color and color perception. However, she has always lived in an entirely black-and-white world. One day she enters a colorful world, and for the first time sees something red. Jackson argues that she has 
learned something new about color (namely, what it is like to see red), so physicalism is false: knowing all of the physical facts does not entail knowing all the facts. Goldie, however, is less interested in this metaphysical conclusion than he is in the premise that Mary has gained a new concept of red. His interpretation of the case (1986: 244) boils down to four claims-

(M1) Mary gains a new phenomenal way of thinking about the experience of seeing red.

(M2) Mary's new way of thinking about the experience of seeing red "subsumes" and "transforms" her earlier way of thinking about it.

(M3) In virtue of (M1) and (M2), Mary gains a new perceptual concept of redone that applies immediately to things in the world, and not just to experiences.

(M4) When Mary employs her new perceptual concept of red in a judgement about something in the world (e.g., That rose is red), the content of this judgement is essentially different than it would have been had she employed her previous, theoretical concept of red.

The substitution of "concept" in (M3) for the broader "way of thinking" in (M1) and (M2) might raise some concern, as might the inference of a new perceptual concept from a new way of thinking about an experience. But setting those concerns aside for present purposes, (M3) does seem to follow from (M1) and (M2), and (M4) follows from (M3) on the relatively uncontroversial assumption that the content of a judgement is determined by the contents of its component concepts. Importantly, an objector could not here "force all the difference into the attitude", since the attitude of judgement remains the same, and the focus is squarely on a presumed change in the judgement's content.

Goldie next sketches out the analogous case of Irene, "an icy-cool icescientist" who knows all of the physical properties and dangers of ice, but who has never before felt fear; she has only an impersonal, theoretical concept of the emotion-

Then, one day, Irene goes out onto the ice, falls, and for the first time feels fear fear towards the dangerous ice. She now knows, "from the inside", what it is like to feel fear, so she has gained a new concept - a phenomenal concept. And she has also gained a new perceptual concept, of dangerousness, of which she previously only had theoretical knowledge. When Irene now thinks of ice as dangerous, she can do so in a new way - in a fearful way: she can now think of it with fear. ...she now understands in a new way what it is for the ice to be dangerous. Before, when she said "That ice is dangerous", the thought expressed 
was a judgement made without feeling; afterwards what she expressed was feeling towards the ice. (p. 245)

If we interpret this case along the lines of the four claims Goldie makes about the Mary case, we arrive at the following-

(I1) Irene has gained a new phenomenal concept of the experience of feeling fear.

(I2) Irene's new phenomenal concept of the experience of feeling fear subsumes and transforms her old concept of it.

(I3) In virtue of (I1) and (I2), Irene gains a new perceptual concept of dangerousness.

(I4) When Irene employs her new perceptual concept of dangerousness in a judgement about something in the world (e.g., That ice is dangerous), the content of this judgement is essentially different than it would have been had she employed her previous, theoretical concept of dangerousness.

Now, the analogy between the Irene and Mary cases clearly breaks down at (I3). For, whatever qualms one might have about inferring (M3) from (M1) and (M2), at least in that case the inference was of a new perceptual concept of red from a new phenomenal way of thinking about the experience of red. But in the Irene case the implicit inference is of a new perceptual concept of dangerousness from a new phenomenal concept of the experience of fear, and the substitution of dangerousness for fear lacks any clear justification. ${ }^{8}$ It is certainly true that Irene can now think of ice as dangerous in a new, fearful way. That is, she can think of ice as dangerous with fear, or even fearfully if we keep in mind the two ways of interpreting such adverbial constructions discussed above. But since (I3) does not seem to follow from (I1) and (I2), we have not been given any reason to believe (I4).

It is tempting to suggest here that Goldie should simply substitute "fearfulness" for "dangerousness" in (I3) and (I4). This would certainly strengthen the analogy to Jackson's case. However, componentialists can agree that when Irene judges "That ice is fearful", she does so with a new concept of fearfulness, and hence that the judgement's content has changed from that of her previous judgements expressed in the same words. But they need not further

8 There certainly is a normative connection between the two concepts: one should fear only what is dangerous, and fears might be rational only when the subject believes that what she fears is dangerous. But no such normative connection can by itself justify the substitution here, since what should be obviously does not entail what is. 
conclude that the content of Irene's concept of ice has changed. For fearfulness, like redness, is arguably a "secondary property"; an object is fearful only in virtue of its effects on the emotional state of a perceiver or thinker. So when Irene thinks "That ice is fearful" with her new concept of fear (and hence with a new concept of something's being fearful), all that may have changed is her conception of ice's effects on her, not her conception of ice per se. ${ }^{9}$ Finally, returning to the original (I3) and (I4), if we allow that Irene has a new perceptual concept of dangerousness entirely in virtue of her new phenomenal concept of the experience of feeling fear, perhaps all that is new in her concept of dangerousness relates to the emotional effects of judging something to be dangerous. If this is right, then once again we would have no reason to think that her concept of ice has changed when she thinks "That ice is dangerous". This is a crucial point, for without the phenomenology of fear "infusing" our concepts of the objects that are feared (or our concepts of the objects that are judged to be fearful or dangerous), a blenderist view of emotion structure is not supported. ${ }^{10}$

\section{Gunther's logical argument for "indissolubility"}

Although York Gunther (2004) has phenomenological arguments for blenderism similar to Goldie's, his most interesting contribution to the program lies in his (2003) argument that linguistic expressions of emotion violate Frege's principle of "force independence". Broadly stated, this principle holds that meaningful sentences or utterances have two distinct parts: a thought-content being expressed, and an attitude with which that content is expressed. ${ }^{11}$ Gunther agrees with Fregeans that force independence helps to explain some aspects of communication, such as how certain questions can properly be answered by merely repeating the words with a different tone of voice. He also agrees it helps to explain how a thought content can be merely entertained rather than asserted, a requirement of conditionals, disjunctions, and negations. But he argues that, because their contents cannot be merely entertained, "emotionally expressive

9 Indeed, the same may be true of Mary, who need not have gained a new concept of rose.

10 The "infusion" metaphor is Goldie's, who writes of emotional episodes, "...phenomenology is neither specifically an aspect of the attitude nor of the content: phenomenology infuses both attitude and content" (2000: 242). If this just means that having the attitude and having a thought with a given content each have their own phenomenologies, or perhaps that they occur in an enveloping cloud of phenomenology (so to speak), it is compatible with componentialism, and even with add-on theories. So it must rather mean that the attitude/content is a blend of feeling and object-identifying representation, a "feeling towards".

11 Cf. Frege (1918/1997: 329), cited by Gunther (2003: 280) to clarify the distinction he has in mind. 
utterances" cannot have conditional or disjunctive contents, and their failure to exhibit such "full logical complexity" indicates that they violate force independence. Finally, he argues that this violation supports the blenderist conclusion that, mentally speaking, emotional feeling and object-identifying content are also not independent. Gunther justifies this last move (from logic to psychology) as follows-

...the correspondence between emotional feeling and force [the attitude of an emotionally expressive utterance] suggests that a difference of force implies a difference of feeling, whereas the intimacy between emotional feeling and content suggests both that a difference of content implies a difference of feeling and a difference of feeling implies a difference of content. If indeed feeling and content are as intimate as that, a compelling explanation is that, in the case of emotions, a difference of force implies a difference of content - or, as I chose to put it [in 2003], force is an indissoluble aspect of content. (2004: 53)

I will not here challenge Gunther's assumption that emotion structure can be inferred from (or explained by) the logic of emotionally expressive utterances, although I find it questionable. Rather, I wish to focus on his initial premise that emotionally expressive utterances cannot have disjunctive or conditional content. For if this premise is false, his argument that emotionally expressive utterances violate force independence fails, and his blenderist conclusion is left unjustified.

Gunther discusses cases involving gratitude and remorse to support his premise that emotionally expressive utterances cannot have disjunctive or conditional content. Regarding gratitude, he claims, "One cannot thank someone for letting you take their class or giving you a passing grade" (2003: 283). That might be true for this particular example, at least absent some specification of a suitably strange context, but the generalization that expressions of gratitude cannot have disjunctive content is clearly false. Suppose, for instance, that I have told you that I wish you would give to charity, and also that I wish you would stop smoking. Suppose further that a third party aware of my wishes informs me that I will be pleased by your behavior. So the next time I see you, before asking which of my wishes you have satisfied, I sincerely say: "Thank you for either giving to charity or stopping smoking." There seems to be nothing illogical about this expression of gratitude, but it has disjunctive content. Gunther's case, then, does not show that emotionally expressive utterances cannot have such content; it merely suggests that in some cases such expressions make little sense.

Similar problems beset Gunther's argument that expressions of remorse cannot have conditional content. Again the general claim rests mainly on a single example: "I cannot apologize that if I come late, I will make a quiet 
entrance." (Ibid.). Admittedly, this apology seems to make little sense. Part of its oddity has to do with its future tense; expressions of regret usually come after the fact. But there certainly are "preemptive" apologies for future events, so let us just agree with Gunther about this apology, and search for a clear counterexample to the general claim. Consider the following case. Suppose that as I enter a formal business meeting, I receive annoyed glances from those already there, and I justifiably infer that either I am late or else I am improperly dressed. I sincerely express my remorse by saying: "I apologize that I am late, or else I am improperly dressed." Like the disjunctive counterexample in the previous paragraph, this seems unproblematic. But an apology with logically equivalent conditional content would be: "I apologize that if I am not late, I am improperly dressed". While few speakers would use the conditional rather than the disjunctive construction, there seems to be nothing problematic about it.

It is important to note, however, that one generally would express regret for $P$ or $Q$ only when one would independently express regret for $\mathrm{P}$ and independently express regret for $\mathrm{Q}$, but one lacks sufficient evidence for expressing either regret singly. This point is not limited to emotionally expressive utterances, for generally one also asserts a disjunction only when one lacks sufficient evidence for asserting either disjunct independently (except in special contexts, such as logic classes). So if one discovered $\mathrm{P}$ to be false, one would express regret for $\mathrm{Q}$, and if one discovered $\mathrm{Q}$ to be false, one would express regret for P. And, given that "or" is being used inclusively in such expressions, one would also express regret for $\mathrm{P}$ and $\mathrm{Q}$ jointly, given adequate evidence. If this is right, then to properly capture the implications of an expression of regret with disjunctive content, one needs to transform it into a conjunction of expressions with conditional content. That is, where $R$ stands for "one expresses regret for", the following seems to hold-

\section{$R(\mathrm{P}$ or $\mathrm{Q})$ if and only if [ $R$ (if not-P, then $\mathrm{Q})$ and $R$ (if not-Q, then $\mathrm{P})$ ]}

This helps to explain, I think, why expressions of regret with conditional content are rare: one would tend to make them only in contexts that call for a conjunction of such expressions, and so only when the expression with disjunctive content would be much more elegant. ${ }^{12}$

Turning from emotionally expressive utterances to emotion ascriptions, Gunther denies that we can properly interpret "Gertrude is happy that if she

12 I am not suggesting that there may not be expressions of regret that properly involve only one conditional. In fact, I am fairly certain that there are. For instance: "I regret that if I have inadvertently killed John, I have devastated his family". However, my guess is that the conditionals that appear in such expressions presuppose causal relations between the antecedent and the consequent, and hence are not logically equivalent to disjunctions of the conditional's negated antecedent and affirmed consequent. 
works hard, she will impress William" as ascribing to Gertrude a state of happiness with conditional content. Rather, we must interpret it as asserting that "if she works hard, Gertrude will be happy that she impresses William" (2003: 283). This is a strained interpretation, since the first statement asserts that Gertrude is presently happy, while the second only predicts that she will be (if she works hard). So it can be justified only if there can be no grounds for the more straightforward interpretation. But there are such grounds. Just imagine that the ascriber witnesses William tell Gertrude that if she works hard, this will impress him. This delights Gertrude, since William is notoriously hard to impress. So she sincerely responds, "I'm happy that if I work hard, I will impress you." I fail to see how Gunther can deny the logical possibility of this scenario, and hence of the straightforward interpretation.

Similarly, Gunther denies that the following utterance has a "genuine" conditional structure: "If Gertrude has skipped class again, damn her, she'll fail the course". If this were a genuine conditional, he claims, "the speaker should be able to entertain rather than experience the antecedent. But this isn't the case" (2003: 284). What is crucial here is Gunther's assumption that an "emotionally experienced content" is incapable of being merely entertained at the time of the experience. But why should we believe this? Is it not the case that merely entertaining - or thinking hypothetically about - a mere possibility can cause one to become (at least mildly) angry? And given that one normally becomes angry about that which causes one's anger, might we not describe the anger in this case as being directed towards the merely entertained possibility that Gertrude has skipped class again? Such anger might not be entirely appropriate, but it would not be unintelligible, and it seems that Gunther requires unintelligibility to argue on logical grounds that this is not a genuine conditional. $^{13}$

Ultimately, Gunther claims that for any expression of emotion with apparent disjunctive or conditional complexity, "it is either (a) grammatically unsound, (b) not an expressive, or (c) not genuinely complex..." (2003: 285). The burden, then, is on Gunther to explain in a non-question-begging way how the proposed counterexamples discussed above fall into at least one of these categories. But if blenderism is as difficult to support as the apparent problems

13 Perhaps Gunther is thinking that if I am angry that $\mathrm{P}$, my attitude toward $\mathrm{P}$ is one of anger, and so it follows by definition (so to speak) that my attitude toward $\mathrm{P}$ is not one of mere hypothetical entertainment. However, interpreting "I am angry that P" as a single propositional attitude - logically on a par with "I hypothetically entertain that P" or "I believe that P" - begs the question in favor of blenderism, and against the componentialist view that to be angry about $P$ is to have an affective state (i.e., a feeling of anger) that can exist without any object-identifying content, plus a properly associated propositional attitude - such as a hypothetical entertainment that P - which essentially has objectidentifying content. 
with Goldie's and Gunther's arguments suggest, the next question to ask is why such capable philosophers have tried to defend it. Gunther suggests at the end of his essay that his blenderist conclusion supports four more general points that interest him: (1) emotions are irreducible to other sorts of mental state; (2) emotional content is unique; (3) the division of labor between psychology and semantics should be reconsidered; and (4) emotions have non-conceptual content (p. 287). But componentialists need not deny any of these points. (1) might follow from a sui generis association between an emotion's affective and object-identifying aspects: emotional feelings seem to be directed at objects in a distinctive way. (2) and (4) could follow from the way in which bodily feelings might represent core relational themes (on a Prinzian sort of view); they need not follow only from blenderism. And regarding (3), componentialists can certainly agree with blenderists that psychology and semantics have much to learn from each other. What seems more relevant to the debate about emotion structure is the relationship between psychology, which aspires to understand the mind from an "impersonal" viewpoint, and phenomenology, which focuses entirely on the personal viewpoint. But to better understand the relationship between blenderism and the personal viewpoint (or between componentialism and the impersonal viewpoint), it will be helpful to locate blenderist concern for the personal viewpoint within a slightly expanded theoretical framework.

\section{The personal and impersonal viewpoints}

Goldie and Gunther are each quite explicit about their interest in defending the personal viewpoint of phenomenology from the impersonal viewpoint of psychology and neurology. Goldie speaks of phenomenology as being in "a different business" than science, and seems to hold that a philosopher interested in developing an ontology of emotion (and thereby at least provisionally settling structural issues) has no reason to prefer the impersonal stance of the latter to the personal stance of the former. For instance, defending his view that bodily feelings might, via a Humean sort of association, "borrow" the intentionality of feelings toward (which he views as non-bodily or "psychic"), Goldie urges us to set aside traditional distinctions-

What we need is an ontology of the emotions, capturable from the perspective of everyday thinking, and faithful to the phenomenology, in which an emotion is what I will call a substantial event, which has certain manifest features: thoughts, feelings, bodily changes, and expressions. ....[These features are] united in the substantial event, which itself has a certain kind of unity, and this unity in turn can be partly explained by the nature of the event. ... With an ontology that puts the philosophical distinction between mind and body as secondary in consideration of 
our emotional lives, we can do justice to the unity of emotional life - lived heart and mind, body and soul. We should not, as Heidegger rightly insisted in another context, "split the phenomenon". (2002: 248)

While the sort of unity Goldie is pressing here is clearly broader than the proposed unity of affect and object-identifying content that constitutes a feeling towards, if the notion of "substantial event" helps to metaphysically ground this broader sort of unity, perhaps it could be used to ground the narrower sort as well. The problem, however, is that this notion is both vague and, philosophically speaking, ad hoc. Goldie needs to argue that "splitting the phenomenon" is somehow less useful or less explanatory than "blending the phenomenon". Absent this, and given the weakness of the arguments discussed above, it seems that the best blenderists can do is to insist that componentialist distinctions are not phenomenologically evident - a point that, as I suggested at the end of section 2, componentialists can accept without changing their presuppositions. $^{14}$

Gunther frames his concern for the personal viewpoint in terms of Frege's "viewpoint constraint" on content ascription: the representational content of a subject's mental state is properly individuated at least in part by its cognitive significance to the subject. For instance, ascribing lust for Jocasta to Oedipus satisfies the constraint; ascribing lust for mother to him does not, even though "Jocasta" and "mother" refer to the same woman in this context. Gunther relies on the viewpoint constraint to reply to an objection to his thesis that "If two emotions have different phenomenologies, they have different contents" (2004: 49). The objection is that when a joke is retold multiple times, the listener is likely to experience less amusement on each rehearing; indeed, eventually she might experience only irritation, but surely this does not entail that the joke's content (the situation it represents) has changed. Gunther replies that this objection "is effectively ignoring the viewpoint constraint. That is, [the objector] is attributing to the individual a kind of content that doesn't capture her viewpoint" (2004: 50). However, this reply begs the question, since we can conclude that the objector is violating the constraint only if we assume that the subject's diminishing amusement alters the joke's content from her viewpoint. Perhaps recognizing this, Gunther goes on to claim that "in such cases intentional psychology has no way of explaining the different kinds of behavior the listener [to the joke] manifests" (Ibid.), such as diminishing laughter. It is not clear just what is meant by "intentional psychology" here; perhaps Gunther is referring to the sort of psychology that attempts to explain behavior entirely in

14 Besides phenomenology itself, perhaps the one area in which phenomenological considerations are paramount is art, fiction and poetry - areas where evocation is more important than literal description. Here blenderism, as an artistic technique, might be quite appropriate. 
terms of feelingless propositional attitudes. But componentialists could explain the different kinds of behavior by hypothesizing successive diminutions of the emotion's affective aspect: the subject finds the retold joke less funny and hence behaves differently simply because it causes her less amusement (she has become inured to it), and not because its content changes from her viewpoint. True, she might describe the joke as being less funny on successive hearings, but all she might mean by this is that it causes her less amusement, not that she finds its content changed..$^{15}$ Indeed, it seems plausible to suppose that she finds it less funny precisely because she recognizes it to be the same joke being tiresomely retold. Gunther's own explanation is that the subject's mode of presentation of the joke's content differs each time, and we cannot describe these different modes of presentation only because we lack the necessary linguistic resources (2004: 50-51). However, this in no way rules out the componentialist explanation, which has the added benefit of requiring no such lack of linguistic resources.

Matthew Ratcliffe (2002a: 56) suggests a broader motivation for the blenderist program: to counter philosophy of mind's tendency to distinguish the affective aspects of mind from those with representational content, and to abstract both from their embodiment. In the case of emotion, Ratcliffe complains that this tendency leads to the sorts of add-on theories discussed above, which view feelings as mere side-effects, or else as merely representing bodily conditions. But whatever one thinks of add-on theories, Prinz clearly demonstrates how a componentialist can view emotions as valent bodily feelings that, by detecting core relational themes, have extra-bodily (albeit not objectidentifying) representational content. Perhaps mainstream philosophy of mind is not as inflexible as Ratcliffe supposes.

Ratcliffe's ultimate target, however, is broader than just the philosophy of mind; it is the notion of scientific objectivity per se. This becomes evident near the end of his essay on William James, whom Ratcliffe interprets (in the light of James' later pragmatism) as being a blenderist himself-

Emotions effectively amount to - though James would hate the term a transcendental precondition for the variously constituted worlds that form the backdrop for deliberation and action. They can be categorized in various different ways, but are themselves pre-conceptual, a constituent of all world-making. Hence James's philosophy is importantly prior to his science... It can, I suggest,

15 The viewpoint constraint is usually considered satisfied if the subject would assent to a particular description of his or her state (as Oedipus would to "lust for Jocasta" but not "lust for mother"), and here we have no reason to think that the subject would withhold assent to "diminished amusement about the joke", where "the joke" refers to the words repeatedly used. 
provide... a conceptual universe that rejects the separation of cognition from affect. (2002b: 195)

Such a "conceptual universe" would be one in which all content is viewed as blended with affect. As Ratcliffe puts it, "One's practical orientation, constituted in part by affect, is integral to the way in which aspects of the world are experientially presented. In other words, it is part of the structure of intentionality" (2005b: 185). The use of "constituted" and "integral" in the first sentence perhaps allows Ratcliffe to validly infer the second. However, he merely assumes that these terms are apt. Elsewhere he tries to support a similar view of intentionality by citing psychiatric studies of schizophrenics (and other delusional persons) that find correlations between altered bodily feelings, affective states, and altered experiences of the world (2005a: 54-56), but he provides no reason to interpret such correlations as indicating anything more than causal influences of a sort that would be completely consistent with componentialism. Finally, we should note that the conceptual framework to which Ratcliffe aspires would view the impersonal, objective standpoint of science as mere pretension, since "any scientific account... is but one of a plurality of different formulas, gelling only with certain concerns" (2002b: 195). But a consistent pragmatism applies to philosophy as well as science. So, on pragmatist grounds, why should componentialists accept blenderism if it does not "gel" with their own explanatory concerns?

Importantly, Ratcliffe's view that all perception is "an indissociable amalgam of organism-independent features and organismic concerns" (2005b: 185 ) is shared by teleosemanticists who, methodologically speaking, stand at the opposite end of the personal-impersonal spectrum. ${ }^{16}$ For instance, on Ruth Millikan's $(1984$; 2004) view of intentionality, a representation's content is determined by its proper function, which is established by how its producers and consumers - different individuals or systems within a single individual - benefit from its use. Since a benefit is always relative to an organismic concern (broadly construed to include needs and interests of which the organism may not be aware), such concerns help to constitute representational content or intentionality, but Millikan certainly does not prefer phenomenology's personal viewpoint over science's impersonal stance.

Finally, while we are on the subject of teleosemantics, we should note that Millikan's denial of attitude/content independence is broader than Gunther's, which, as we saw, applies only to emotionally expressive utterances (and hence, he thinks, to emotions themselves). Millikan writes-

16 Indeed, it is shared by all those who hold a Gibsonian or neo-Gibsonian "affordance theory" of perception. Cf. Gibson, 1977. 
Frege's notion of sense, which implied that you can first represent a proposition and then add an intentional attitude to it, has done a lot of damage, I believe. There are not and could not be intentional representations that lacked attitude. There are no intentional representations without purposes, and having a purpose guarantees attitude. (2004: 81)

Clearly, denying attitude/content independence no more entails a preference for the personal viewpoint than does viewing organismic concerns as partly constitutive of intentionality. In fact, Millikan's view shows that the attitude/content debate is actually orthogonal to the blenderist/componentialist debate. For even if content always "comes with" attitude, this does not settle the question of whether emotions with object-identifying content consist of one attitude/content (in which the affective and object-identifying aspects are indissociably blended), or of two dissociable ones. Prinz, for instance, could deny attitude/content independence without altering his componentialism an iota. For he could easily view emotional feelings as assertorically detecting core relational themes (where to "assertorically detect" a core relational theme is to represent it as actually holding between oneself and whatever the emotion's object-identifying aspect represents, as opposed to merely hypothetically entertaining that it might hold), and he could view the states that provide those feelings with object-identifying aspects as necessarily representing them with particular attitudes. Of course, emotion ascriptions like "I am glad that my computer is working" might still be viewed as misleading on such a view, but only because their surface grammar could be too suggestive of ascriptions of single propositional attitudes. On the Millikan/Prinz view being imagined ${ }^{17}$, they should rather be interpreted as ascribing pairs of closely associated but yet dissociable states, each member of the pair being an indissociable blend of attitude and content.

\section{Concluding remarks}

While none of the arguments for blenderism discussed above seem convincing, there may be a strong argument for the view that I have missed, or one yet to be formed. In the meantime, componentialism retains some advantages. First, as Lazarus and Prinz each illustrate, the ontology associated with componentialism allows us to integrate emotion into our larger theory of mind without

17 Such a view is further suggested by the fact that Prinz's theory of emotion fits neatly into Millikan's "pushmi-pullyu" model of simultaneously descriptive and directive representation (Cf. Millikan, 2006, chapter 6), for as embodied appraisals representing core relational themes, emotional feelings are "descriptive" in Millikan's broad sense, and as valent states they are directive. 
unnecessarily multiplying types of representational content. Secondly, it allows us to easily describe and explain common instances of affective inertia and displacement, phenomena that blenderists should have a harder time explaining. Thirdly, phenomenology per se does not support blenderism over componentialism, for even if blenderist intuitions hold, Damasio's view of emotional feeling shows how the "superposition" of affect and objectidentifying content in personal experience might mask a "juxtaposition" at a deeper level. Fourthly, unlike mere add-on theories, componentialist theories do not entail any reduction of emotion to non-emotional states, since emotional feelings might represent core relational themes or motivate behaviors in unique ways, and the association of an emotion's affective aspect with its objectidentifying aspect might well be sui generis. Finally, while componentialism might view impersonal explanation as trumping personal experience for the purpose of developing a philosophical ontology and scientific psychology of emotion, it need claim neither that the personal viewpoint is reducible to the impersonal, nor that the philosophy of mind should be guided only by psychology. Indeed, it seems to me that the best way to view the relationship between phenomenology and psychology is not as a competition at all, but rather as a cooperative venture, and one that the philosophy of mind should help to facilitate.

\section{References}

Damasio, A. R. (1994). Descartes' Error: Emotion, Reason and the Human Brain, New York: Avon Books.

Damasio, A. R. (2004). 'William James and The Modern Neurobiology of Emotion.' In: Evans, D. and Cruse, P. (eds.). Emotion, Evolution, and Rationality, New York: Oxford University Press (USA), 3-14.

De Sousa, R. (1987). The Rationality of Emotion, Cambridge MA: The Massachusetts Institute of Technology Press.

Descartes, R. (1649/1985). 'Passions of the soul.' In: Cottingham, J., Stoothoff, R. and Murdoch, D. (eds.). The Philosophical Writings of Descartes, Vol. 1, Cambridge: Cambridge University Press, 325-404.

Frege, G. (1918/1997). 'Thought.' Reprinted in Beany, M. (ed.), The Frege Reader, Oxford: Blackwell, 325-345.

Gibson, J. J. (1977). 'The Theory of Affordances.' In: Shaw, R. and Bransford, J. (eds.), Perceiving, Acting, and Knowing: Toward an Ecological Psychology, Hillsdale, NJ: Erlbaum. 67-82.

Gunther, Y. (2003). 'Emotion and Force.' In: Gunther, Y. (ed.), Essays on Nonconceptual Content, Cambridge, MA: The Massachusetts Institute of Technology Press, 279-288.

Gunther, Y. (2004). 'The Phenomenology and Intentionality of Emotion.' Philosophical Studies, 117, 43-55.

Goldie, P. (2000). The Emotions: A Philosophical Exploration, Oxford: Oxford University Press. 
Goldie, P. (2002). 'Emotions, feelings, and intentionality.' Phenomenology and the Cognitive Sciences, 1, 235-254.

Gordon, R. M. (1987). The Structure of Emotions: Investigations in Cognitive Philosophy, Cambridge: Cambridge University Press.

Hume, D. (1739/1975). A Treatise of Human Nature. In: Selby-Bigge, L. A. (ed.), 2nd edition revised by P. H. Nidditch, Oxford: Clarendon Press.

Jackson, F. (1986). 'What Mary Didn't Know.' Journal of Philosophy, 83, 291-295.

Lazarus, R. S. (1991). Emotion and Adaptation, New York: Oxford University Press.

Lazarus, R. S. (1999). 'The Cognition-Emotion Debate.' In: Dalgleish, T. and Power, M. (eds.), Handbook of Cognition and Emotion, West Sussex: John Wiley and Sons Ltd., 319.

Millikan, R. G. (1984). Language, Thought, and Other Biological Categories: New Foundations for Realism, Cambridge, MA: The Massachusetts Institute of Technology Press.

Millikan, R. G. (2004). Varieties of Meaning: the 2002 Jean Nicod lectures, Cambridge MA: The Massachusetts Institute of Technology Press.

Prinz, J. J. (2004). Gut Reactions: A Perceptual Theory of Emotion, New York: Oxford University Press.

Ratcliffe, M. (2005a). 'The Feeling of Being'. Journal of Consciousness Studies, 12 (8-10), 43-60.

Ratcliffe, M. (2005b). 'William James on Emotion and Intentionality'. International Journal of Philosophical Studies, 13 (2), 179-202.

Solomon, R. C. (1984). 'Emotions and Choice.' In: Calhoun, C. and Solomon, R. C. (eds.), What is an Emotion?, Oxford: Oxford University Press. 